\title{
Autolesão não suicida e contexto escolar: perspectivas de adolescentes e profissionais da educação*
}

\author{
Luiza Cesar Riani Costa ${ }^{1,2}$ \\ (D) https://orcid.org/0000-0003-3182-3408 \\ Isabela Martins Gabrie|1,2 \\ (D) https://orcid.org/0000-0001-6447-6110 \\ Daniela Gonsalves Lopes ${ }^{1}$ \\ (D) https://orcid.org/0000-0003-2240-1772 \\ Wanderlei Abadio de Oliveira ${ }^{3}$ \\ (D) https://orcid.org/0000-0002-3146-8197 \\ Jorge Luiz da Silva ${ }^{4}$ \\ D https://orcid.org/0000-0002-3727-8490 \\ Diene Monique Carlos 1 \\ (D) https://orcid.org/0000-0002-4950-7350
}

Objetivo: compreender as relações entre o contexto escolar e a Autolesão Não Suicida (ALNS) na perspectiva de adolescentes que se autolesionaram e profissionais da educação. Métodos: Pesquisa qualitativa, cujos participantes foram 8 adolescentes e 15 profissionais de educação de uma escola de um municipio do interior de São Paulo. A coleta de dados com as adolescentes foi com entrevistas individuais utilizando o Desenho-Estória com Tema; com os profissionais foi o grupo focal, com uso de Diário de Campo. Os dados foram analisados pela Análise Temática; o referencial teórico foi a teoria psicanalítica winnicottiana. Resultados: Emergiram os temas "O (não) lugar do sofrimento na escola" e "Ações para enfrentamento da ALNS na escola". Os dados demonstraram a existência de um ambiente pouco saudável ao desenvolvimento adolescente, sendo pouco acolhedor frente ao bullying e a ALNS. As ações realizadas pela escola, apesar de pouco legitimadas pelos profissionais, foram reportadas como suporte para enfrentamento da ALNS pelas adolescentes. Conclusão: O estudo traz importantes contribuições para o cuidado integral em saúde mental adolescente, visto que a intersetorialidade é inerente a tal aspecto. A interface saúde-escola ainda precisa de esforços para que se efetive na prática; tal estudo traz subsídios para este aprimoramento.

Descritores: Adolescente; Comportamento Autodestrutivo; Pesquisa Qualitativa; Pessoal de Educação; Psicanálise; Serviços de Saúde Escolar.

\section{Como citar este artigo}

Costa LCR, Gabriel IM, Lopes DG, Oliveira WA, Silva JL, Carlos DM. Non-suicidal self-injury and school context: perspectives of adolescents and education professionals. SMAD, Rev Eletrônica Saúde Mental Álcool Drog. 2020;16(4):39-48. doi: https://dx.doi.org/10.11606/issn.1806-6976.smad.2020.168295 


\section{Non-suicidal self-injury and school context: perspectives of adolescents and education professionals}

Objective: to understand the relation between the school context and Non-Suicidal Self Injury (NSSI) from the perspective of adolescents who self-injured and their education professionals. Method: a qualitative research whose participants were 8 adolescents who selfinjured, and 15 education professionals from a school in the inland of São Paulo. Data collection with the adolescents was performed through individual interviews using the Drawing-Story with Theme Procedure. The methodological strategy used with the professionals was a Focus Group, using a Field Diary. The data were analyzed by Thematic Analysis; the theoretical framework was Winnicott's psychoanalytic theory. Results: the themes "The (non) place of suffering at school" and "Actions to face NSSI at school" emerged. The data demonstrated the existence of an unhealthy environment for adolescent development, unfriendly in the face of bullying and NSSI. The actions taken by the school, although little legitimized by the professionals, were reported as support for coping with NSSI by the adolescents. Conclusion: the present study brings important contributions to comprehensive adolescent mental health care, since inter-sectorality is inherent in this aspect. The health-school interface still needs efforts to become effective in practice; this study provides subsidies for this improvement.

Descriptors: Adolescent; Educational Personnel; Qualitative Research; Psychoanalysis; School Health Services; Self-Injurious Behavior.

\section{Autolesion no suicida y contexto escolar: perspectivas de adolescentes y profesionales de la educación}

Objetivo: comprender la relación entre el contexto escolar y la Auyolesión No Suicida (ALNS) desde la perspectiva de adolescentes que si autolesionaron y profesionales de la educación. Métodos: Es una investigación cualitativa cuyos participantes fueron 8 adolescentes que si autolesionaron y 15 profesionales de la educación de una escuela en el interior de São Paulo. La recopilación de datos con los adolescentes se realizó a través de entrevistas individuales utilizando DibujosHistórias con Temática y Grupo Focal con los profesionales, utilizando el Diario de Campo. Los datos fueron analizados por análisis temático; el marco teórico fue la teoría psicoanalítica de Winnicott. Resultados: Los datos demostraron la existencia de un entorno poco saludable para el desarrollo de los adolescentes, siendo poco acogedor frente al bullying y la ALNS. Las acciones tomadas por la escuela, aunque poco legitimadas por los profesionales, fueron reportadas como apoyo para hacer frente a ALNS por parte de los adolescentes. Conclusión: El presente estudio aporta importantes contribuciones a la atención integral de la salud mental de los adolescentes, ya que la intersectorialidad es inherente a este aspecto. La interfaz salud-escuela aún necesita esfuerzos para ser efectiva en la práctica; este estudio proporciona subsidios para esta mejora.

Descriptores: Adolescente; Conducta Autodestructiva; Investigación Cualitativa; Personal Docente; Psicoanálisis; Servicios de Salud Escolar. 


\section{Introdução}

Observa-se que a prática da Autolesão Não Suicida (ALNS) entre os adolescentes tem aparecido tanto no ambiente escolar como no domiciliar(1). A ALNS pode ser definida como lesão deliberada que resulta na destruição direta ou alteração do tecido corporal de quem a praticou. Este conceito engloba qualquer comportamento intencional que envolva agressão direta ao corpo, sem intenção de chegar ao suicídio, e não aceita socialmente ${ }^{(2)}$. Algumas das manifestações são cortes superficiais na pele, arranhões, mordidas, queimaduras, bater partes do corpo contra a parede e introduzir objetos pontiagudos no corpo(2).

O Boletim Epidemiológico do Ministéiro da saúde indica a presença de ALNS entre adolescentes no Brasil(3). Estatísitcas internacionais apontam que aproximadamente $15 \%$ dos adolescentes se autolesionam, acusando uma leve prevalência entre mulheres ${ }^{(4)}$. O fato deste evento ocorrer de forma prevalente entre adolescentes está relacionado a questões multifatoriais. O processo de adolescer é considerado hoje como uma categoria social com implicações diretas do momento histórico, político e social( $^{(5)}$. A ALNS emerge como forma de enfrentamento de emoções(6). Por necessitar de um contexto de apoio para se desenvolver, o fenômeno da ALNS na adolescência é geralmente associado a relacionamentos interpessoais negativos ${ }^{(7)}$. A literatura indica que tal fenômeno seja vislumbrado como um comportamento significante na adolescência e não como um sintoma de uma doença(6).

Neste processo, o contágio pode estar presente entre grupos de adolescentes, inclusive por características de grupalidade presentes nesse momento. Pode também se relacionar frente ao sofrimento emocional causado pela falta de atenção por familiares, amigos e até mesmo bullying em sala de aula ou nas dependências da escola(2). Denota-se a relevância do contexto escolar neste percurso; o mesmo aparece como principal meio de socialização na adolescencência, onde experimentam suas identidades para além das famílias ${ }^{(8)}$.

Considerando o exposto, traz-se enquanto questão norteadora: Qual as relações existentes entre o contexto escolar e a ALNS? Qual o papel deste contexto no enfrentamento e prevenção deste fenômeno? Tais questões podem colaborar na resposta a lacunas científicas na temática, e corroboram políticas como o Programa Saúde na Escola e, mais atualmente, a Política Nacional de Prevenção da Automutilação e do Suicídio (Lei 13819, de 26 de abril de 2019).

Para tal aproximação, apoiamo-nos na Teoria do Amadurecimento de D. W. Winnicott( ${ }^{(9)}$. Para este autor, a saúde mental tem como um de seus fundamentos a concepção de que todo indivíduo humano é dotado de uma tendência inata para o amadurecimento. Apesar de inata, essa tendência não se realiza sozinha pois não se refere a uma determinação(9). Para que essa tendência se realize e seja atingida a saúde de forma integral, o sujeito depende fundamentalmente da presença de um ambiente facilitador que forneça cuidados suficientemente bons, e que possibilite a realização de processos de integração(9). Assim, na perspectiva winnicottiana, as condições ambientais (considerando ambiente tudo aquilo que influencia e é influenciado pelo sujeito, como o ambiente físico e as relações pessoais) são decisivas para o estabelecimento da saúde do sujeito ao longo de todo o processo de desenvolvimento(9). Neste sentido, tal referencial se mostra coerente a este objeto, considerando a importância do ambiente escolar ao desenvolvimento saudável de adolescentes.

Assim, o objetivo deste estudo foi compreender as relações entre o contexto escolar e a ALNS na perspectiva de adolescentes que se autolesionaram e profissionais da educação.

\section{Método}

Pesquisa de abordagem qualitativa, entendida como aquela destinada ao estudo das relações sociais; permite o reconhecimento das perspectivas dos participantes, diretamente envolvidos em determinado fenômeno, e o respeito às suas singularidades e diversidades. A reflexão do pesquisador em sua pesquisa é parte do processo de produção de conhecimento; existe a possibilidade e variedade de aproximações e técnicas. O olhar para o contexto particular, local e temporal é aspecto importante para a descrição histórica, específica e concreta de sistemas de conhecimentos, práticas e experiências ${ }^{(10)}$. Conforme já sinalizado, o referencial teórico utilizado foi a teoria psicanalítica de Winnicott, que delineou o percurso metodológico exposto a seguir.

$O$ estudo foi realizado em um município do interior de São Paulo. A cidade possui 221.950 habitantes de acordo com censo de 2010, com estimativa para 2018 de 249.415 habitantes. A população de 10 a 19 anos é de 33.169 pessoas, cerca de $15 \%$ do total da população(11).

O campo específico foi uma escola estadual de ensino fundamental e médio de um distrito do município. A escolha por este local se deu devido (i) a existência de um projeto de extensão da universidade neste local; (ii) o crescente número de situações de automutilações por adolescentes reportadas aos serviços de saúde do município; (iii) a ausência de intervenções neste campo por ser bastante periférico.

Os participantes foram adolescentes com história de ALNS e profissionais da educação. As adolescentes foram incluídas mediante os critérios: (1) ser estudante 
matriculado na escola citada; (2) ter idade entre 10 e 19 anos; (3) ser indicado pela direção ou professores por vivenciar situações de automutilação. Foram excluídos os adolescentes afastados do convívio escolar por quaisquer motivos. A direção da escola indicou oito adolescentes do sexo feminino que haviam relatado situações de automutilação; este relato veio das próprias adolescentes ou de familiares. Antes do início da coleta de dados, a direção realizou contato com os pais para anuência da participação das adolescentes. As pesquisadoras realizaram uma primeira conversa com as adolescentes, para convidá-las a participar do estudo, e todas aceitaram.

Os profissionais da educação foram incluídos mediante os critérios: (1) ser profissional da escola citada; (2) ter contato direto passado ou presente com adolescentes que se autolesionaram; (3) estar trabalhando nos serviços há pelo menos seis meses. Foram excluídos os profissionais que não estavam em exercício ativo nos serviços durante o período de coleta de dados.

A estratégia de coleta de dados adotada junto às adolescentes foi o uso da Consulta Terapêutica individual, mediada pelo recurso dialógico Procedimento DesenhoEstória com Tema, sendo que o tema apresentado foi automutilação.

Consulta terapêutica é uma técnica desenvolvida por Winnicott que consiste em poucos encontros (um a três), conta com o uso de um mediador dialógico para expressão e privilegia o acolhimento dos conteúdos emergentes(12). A consulta terapêutica se respalda em uma comunicação significativa entre terapeuta e paciente (neste caso, pesquisador e participante, respectivamente), sendo utilizada como diagnóstico e como instrumento de pesquisa dos conteúdos que estão afligindo o participante.

Winnicott indica que a comunicação significativa deve ser atingida para que haja possibilidade de promoção de saúde, e que esta aparece com relativa facilidade durante suas sessões por meio de brincadeiras, desenhos e jogos. Utilizar-se de mediadores dialógicos cria um ambiente que favorece a aproximação do indivíduo a questões angustiantes e de difícil acesso ${ }^{(9)}$. Considerando tais apontamentos, escolheu-se neste estudo utilizar o Procedimento Desenho-Estória com Tema de Aiello-Vaisberg(13). Este procedimento consiste em solicitar ao participante que faça um desenho com um tema pré-determinado pelo pesquisador. Ao terminar o desenho, ele deve contar a história de sua produção gráfica. O pesquisador realiza os mesmos passos que o participante. Ao término dessa fase, ambos mostram seus desenhos e contam suas histórias. A escolha deste procedimento deve-se à sua característica de facilitar a imersão de conteúdos de difícil expressão oral $^{(13)}$, considerando que, conforme referenciado na introdução, a literatura relaciona a automutilação com a dificuldade de expressividade e comunicação. Antes do início do procedimento Desenho-Estória com Tema, a pesquisadora fez uma breve entrevista com caráter sociodemográfico.

A coleta de dados junto aos profissionais da educação foi realizada por meio de grupo focal, sendo moderado pela última autora e observado pela primeira e segunda autora, com o uso do diário de campo. Os participantes foram convidados previamente na escola por meio de reunião de planejamento pedagógico. Três profissionais se recusaram a participar.

A coleta de dados foi realizada no período de 30 de julho a 06 de outubro de 2019, numa sala privativa na própria escola. As falas foram gravadas em aparelho celular Samsung, com aplicativo próprio de gravação de voz. O processo de desenho e consulta junto às adolescentes teve duração entre 30 e 55 minutos. Já o grupo focal com os profissionais, teve duração de 1 hora e 49 minutos.

Após gravação, os áudios foram transcritos na íntegra, sendo os nomes presentes neste artigo fictícios, escolhidos pelas adolescentes; nas falas dos profissionais, utilizou-se o $\mathrm{PE}$, sendo enumerados na orden em que apareceram no grupo. Neste estudo buscou-se a saturação de significado; esta corresponde a uma discussão mais profunda, rica em detalhes e complexa com os dados para assegurar a compreensão de um fenômeno de interesse ${ }^{(14)}$. A coleta de dados foi encerrada quando se alcançou esta saturação.

Os dados foram analisados a partir da técnica de análise temática ${ }^{(15)}$. A análise temática é essencialmente um método para identificar e analisar padrões de dados qualitativos. Foram seguidos os seguintes passos para análise: (I) familiarização com os dados: após transcrição dos áudios, foram realizadas leituras e releituras exaustivas do conjunto de dados, articulados aos dados presentes nos desenhos; (II) codificação: buscou-se referenciar e codificar as informações relevantes em função das questões de pesquisa, por meio de códigos que capturam a leitura semântica e conceitual dos dados; (III) busca por temas: os códigos da fase anterior foram agrupados em temas; (IV) revisão de temas: checagem se os temas trabalham de acordo com os códigos de dados extraídos e sua relação com o conjunto geral de dados, para serem representativos; (V) definição e nomeação dos temas: conduziu-se a escrita detalhada da análise de cada tema, identificando a essência de cada um; (VI) escrita final: elemento integral da análise temática, que envolve a tessitura conjunta da narrativa analítica, bem como sua contextualização com literatura relevante da área, dispositivos legais e articulação com os conceitos teóricos. 
Da análise dos dados, emergiram dois temas "O (não) lugar do sofrimento na escola" e "Ações para enfrentamento da ALNS na escola". Para garantir maior validade e confiabilidade dos dados, foram realizadas as seguintes estratégias: devolutiva dos dados aos participantes em encontro posterior para "checagem" da coerência do conteúdo; análise com pares, ou seja, a construção dos códigos e temas se deram por dois pesquisadores independentes e validados por um terceiro quando foi necessário; uso do diário de campo, garantindo maior transparência de todo o processo de pesquisa.

A pesquisa atendeu aos aspectos éticos envolvendo seres humanos, sendo aprovada pelo Comitê de Ética da Universidade Federal de São Carlos (CAAE: 17176219.6.0000.5504), e autorizada pela escola cenário da pesquisa. Reitera-se que as informações foram coletadas apenas após assinatura do Termo de Consentimento Livre e Esclarecido pelos profissionais e responsáveis pelas adolescentes e do Termo de Assentimento Livre e Esclarecido pelas adolescentes.

\section{Resultados}

Em termos de caracterização, todas as participantes do estudo eram do sexo feminino, sendo duas de 12 anos, quatro de 13 anos, e duas de 14 anos. Cinco das adolescentes estavam no sétimo ano do ensino fundamental e três no oitavo ano do ensino fundamental. Em relação à religião, metade das participantes afirmou ser católica, duas afirmaram ser evangélicas e duas declararam não ter religião. A quantidade de pessoas que viviam na mesma casa variou entre três e seis pessoas, sendo que todas moravam com a mãe, e os outros membros variaram entre pai, padrasto, irmãos e diferentes familiares. Quanto à escolaridade dos responsáveis, a menor escolaridade foi não saber ler nem escrever (responsáveis por uma participante) e a maior foi ensino médio completo (mães de duas participantes e pai de uma).

Os profissionais da educação foram 15 professores do ensino fundamental e médio na escola citada. Dentre eles, dois eram do sexo masculino e os demais, do sexo feminino. Dois profissionais possuíam entre 21 e 30 anos; cinco entre 31 e 40 anos; quatro entre 41 e 50 anos e quatro entre 51 e 60 anos. A formação profissional era composta por Geografia, História, Artes, Pedagogia, Letras, Português, Matemática, Educação Física e Química. Um profissional teve o tema da ALNS na sua formação profissional, e nenhum dos professores participou de atualização sobre o tema durante a atuação profissional.

A seguir são exploradas os temas identificados no estudo.

\section{Tema 1 - $O$ (não) lugar do sofrimento na escola}

Neste tema apresentamos falas que dizem respeito às relações disfuncionais dentro do contexto escolar, e suas possíveis consequências, tanto na perspectiva das adolescentes quanto dos profissionais de educação. Quando questionadas a respeito da convivência escolar, as adolescentes trouxeram relatos de relações pouco saudáveis entre pares, em que elas aparecem como vítimas de violência escolar: E na sala de aula mesmo, as pessoas as vezes me zoam, falam que eu sou estranha porque eu escrevo com a outra mão. E tem um menino que antes das férias chegou a falar que eu era um lixo, essas coisas. Aí eu fui começando a me sentir mal por isso. Minhas amigas mesmo, tem dias que elas falam pra mim também, elas tentam falar na zueira, mas eu levo pra dentro... Eles fazem o que quer, como se você fosse um objeto. Eles falam palavras pra você, mesmo que seja zuando, machucam. Ah, chegaram a me falar que eu sou mesmo substituível pra todo mundo. Um menino já falou que eu sou um lixo, e tem hora assim que eu passo perto das pessoas, ali na sala, e eles fazem aquela cara como se tivesse nojo da pessoa, sabe? Aí eu vou ficando pra baixo. Que nem, lá na sala eu só fico no meu canto, não falo muito com ninguém, fico quieta, pensando. (Marina); Antes eu chorava muito quando eu ficava triste, aí começaram e me chamar de chorona, falar que eu era chorona (aqui na escola) (Amanda).

Como consequência, as adolescentes relataram sentimentos negativos, tristeza, exclusão. Foi apontada a relação direta entre o bullying e a ocorrência da ALNS, como exemplificado na Figura 1.

Eu desenhei um povo jogando futebol, em uma quadra. Só que aí ele fazem bullying com uma das meninas. Tipo, ela é forte, meio fortinha, e ela tá jogando bola e um deles fala que ninguém sabe qual é a bola. Esse tipo de brincadeira de mal gosto. (...) Eu tava na recreação, um lugar que nós vai pra brincar. Aí tem professor, só que o professor não viu. Aí eu fiquei quieta, mas depois eu chorei, e fiquei mal. (...) Muitas meninas sofrem bullying e depois se cortam (Renata); Isso (autolesão não suicida) começou quando eu tava no terceiro ano, eu comecei a sofrer bullying. Começaram a me zuar (Dafne).

Os professores reconheceram a existência de relações não saudáveis, em especial o bullying na escola; entretanto suas falas demonstraram não reconhecimento do sofrimento que tal contexto gera para os adolescentes: E não sabe se defender porque tudo é bullying, se você não defende ele em sala de aula ele vai surtar, ele vai matar, ele vai morrer, vai usar droga, beber (Fabiana); Na nossa escola tinha aquele negócio de chamar de gordinho, de magricelo, de branquelo e isso não era bullying, hoje é. Hoje se você falar "seu amarelo" Deus me livre, o cara chama a polícia, ou seja, hoje tudo está exagerado, hoje todos os sentimentos estão exagerados (Carlos). 


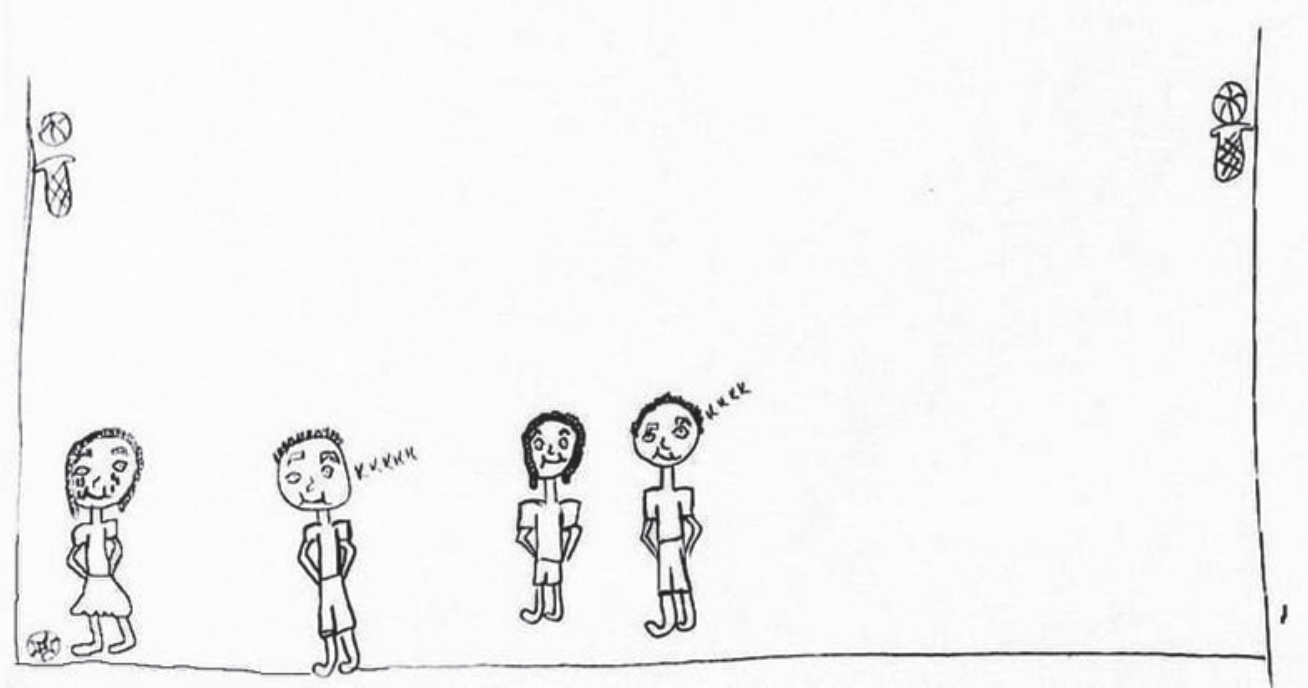

Figura 1 - Desenho-Estória com Tema de Renata. Interior de São Paulo, 2019

Explicitaram diferenças percebidas entre a própria geração e a geração atual, baseando suas compreensões e percepções nestas vivências pessoais. Ainda neste sentido e reforçando o estereótipo apontado anteriormente, explicitaram que o fenômeno da ALNS é relacionado ao não preparo para lidar com frustrações: $E$ aquele ensino contínuo da frustração, que hoje em dia a criança não pode se frustrar, e quando eles crescerem obviamente eles vão se frustrar e não sabem lidar com esse sentimento, pois não aprenderam a lidar, a passar por cima da frustração, minha mãe e meu pai não me permitiram sofrer (Sueli);. Eu também sou da geração 70 e nunca ouvi falar, minhas amigas nenhuma se cortou, se matou, mas deve ter acontecido, um ou dois casos, mas não como nos dias de hoje (Fabiana).

\section{Tema 2 - Ações de enfretamento à ALNS na escola}

Neste tema, esteve presente nas falas das adolescentes as ações realizadas pelos profissionais da educação, tanto para casos de bullying como para casos de ALNS, e o quanto elas impactaram no enfrentamento das mesmas. A escola é apontada, em algumas situações, como único espaço de proteção e acolhimento: Até que eu tinha um potinho cheio de lâmina, mas aí a dona pegou. Eu acho que se a Eudóxia não tivesse tirado as lâminas eu já tinha feito alguma coisa. Porque cada dia que passava eu aumentava mais a profundidade dos cortes... (Marina);. As pessoas me colocavam cada vez mais pra baixo. Até que eu fiz um trabalho sobre depressão com o professor João. Era um trabalho sobre tema livre, e eu escolhi fazer sobre depressão e automutilação. todo mundo falava que isso era frescura minha, que isso é uma fase que já vai passar, que é só tristeza, e assim eram os comentários... o professor acho que conversou com eles porque no dia seguinte eu faltei, e ele conversou com eles falou que isso era sério, que não era brincadeira. Daí em diante eles começaram a melhorar as falas comigo, ficaram mais próximos, perguntavam se eu tava bem... (Letícia)
Denota-se a importância deste contexto para as adolescentes, bem como ações relevantes para melhor enfrentamento da ALNS - o acolhimento, a redução de danos pela retirada das lâminas e promoção de conhecimentos sobre saúde mental. Ainda existiram situações da escola realizar a articulação com a família: Teve um dia que eu me cortei aqui na escola, e o professor João viu. Ele me encaminhou aqui pra Emilia pra eu conversar com ela. Ai a Emilia contou pra minha mae que eu tava me cortando (Letícia).

Neste sentido, os profissionais também trouxeram a implicação na construção de ambientes mais saudáveis e a realização de ações para promoção de saúde mental dos estudantes: Primeira coisa que vem na minha cabeça é notificar os pais, eu tenho que fazer alguma coisa né, eu tenho que buscar onde eu pelo menos acredito que possa ter algum espaço de ajuda, de apoio para essa pessoa... (Janete); . Mas às vezes só o fato de ouvir, dela desabafar e você ouvir, nem precisa dialogar, que ela coloque se ouça, já ajuda muito (Eliane); Tem que conversar, entender o que ta acontecendo (Adriana).

Alguns profissionais relataram que tal manejo não está dentro de sua governabilidade, essencialmente pela falta de conhecimento na área: Quando uma criança ta com dor de cabeça, a escola pode medicá-la? Não pode! Então, se a escola não tem essa função em medicá-los em determinadas situações eu não tenho como estar a par da situação... a única coisa que eu posso fazer é mandar para intermediação e Conselho Tutelar. Da mesma forma que eu não posso medicar o cara eu não posso ficar aconselhando (Roberto).

A responsabilidade colocada pelos profissionais da educação, por muitas vezes serem a porta de entrada das diversas situações que ocorrem com os adolescentes, foi um tema discutido; os mesmos trouxeram a emergente necessidade de educação permanente na temática: A escola é o principal local que 
essas coisas acabam desencadeando e nós acabamos sendo o que? Os receptores de toda essa situação e você ter que intermediar, ter que falar com a família que seu filho está se mutilando, aí entra os valores, as posturas que as pessoas estão tomando, mas o principal que é essa pessoa que ela ta se mutilando, o que ia dar para fazer com ela? Onde vamos buscar argumento para conversar com esse indivíduo que está se mutilando porque não sabemos o que já ocorreu nas suas vivências, não estamos preparados para essa gama de transformações que nós temos que estar preparados. Nós temos que estar preparados e não estamos preparados (Emilia).

\section{Discussão}

As perspectivas das adolescentes que se autolesionam e dos profissionais da educação acerca da interface escola-ALNS apontam para a relevância do ambiente escolar na saúde dos adolescentes, e para a incerteza do papel que a escola deve tomar frente aos casos de ALNS. Tanto as adolescentes quanto os profissionais reconheceram a existência de bullying na escola, que foi apontado pelas adolescentes como um fator importante para que se autolesionem. Apesar de ter sido citado por ambos, as percepções a respeito do sofrimento que o bullying pode causar diferiram. Ademais, o não lugar de acolhimento à ALNS, a despeito de algumas ações e desejos pontuais, foi desvelado.

Ao falarmos sobre a importância do ambiente escolar, é necessário compreender antes a importância do ambiente como um todo. Winnicott traz a ideia de que, para atingir o amadurecimento saudável é necessária a presença de um ambiente suficientemente bom que facilite os processos do desenvolvimento( ${ }^{(9)}$. É necessário que haja um ambiente (físico, relacional, social) que forneça cuidado e sustentação para possibilitar que tendência inata ao amadurecimento e à saúde psíquica se realize ${ }^{(9)}$. Vale ressaltar, que o ambiente na obra de Winnicott é um conceito rico e complexo, composto por tudo aquilo que cerca o sujeito(9).

O primeiro ambiente que nos cerca, ainda quando bebês, é a mãe (ao utilizar o termo mãe, estamos nos referindo a qualquer pessoa que seja a responsável principal pelos cuidados do bebê). Nascemos no estado de dependência absoluta, sendo que dependemos dos cuidados maternos para sobreviver. De acordo com o psicanalista, após o nascimento o bebê depende absolutamente do ambiente que o sustenta, e com o decorrer do desenvolvimento, vai se tornando capaz de conhecer novos ambientes e amadurecer rumo à independência relativa(9). $O$ ingresso em instituições de educação infantil fornece oportunidade da extensão do convívio familiar para o convívio social. A escola representa uma intermediação entre a dependência absoluta e o amadurecimento rumo à independência ${ }^{(16)}$.
Assim, o ambiente escolar mostra-se fundamental no amadurecimento das crianças e adolescentes, essencial tanto na saúde psíquica, quanto na introdução aos agrupamentos sociais e à cultura. $\mathrm{O}$ ambiente escolar pode, então, oferecer oportunidade de desenvolvimento sadio para os adolescentes, no caminho de se tornarem adultos independentes. Da mesma forma, um ambiente escolar que não sustenta e não acolhe, pode acarretar em sofrimento psíquico(16).

As adolescentes deste estudo relataram situações de ALNS envoltas pelo bullying na escola. O bullying, como parte do ambiente escolar, apresenta-se às adolescentes como fonte de angústia, tristeza e isolamento. Estudo desenvolvidos em amostra de escolas belgas e holandesas, junto a 785 adolescentes, investigou a associação de ALNS e bullying, dentre outras variaveis; sofrer bullying aumentou o risco da ocorrencia de $\operatorname{ALNS}^{(17)}$. Frente a um ambiente não saudável, que proporciona sentimentos negativos e não acolhe, as adolescentes recorreram à ALNS como forma de lidar com o sofrimento; tal aspecto é reforçado por estudo desenvolvido com 856 adolescentes, em que 103 relataram episódios de ALNS motivados pelo alivio de um sentimento ruim, em sua maioria(6). Estudo inglês em uma população urbana, étnicamente diversa, encontrou que a ALNS trata de uma expressão singular de angustia emocional, com fragilidade para busca de ajuda(18).

Portanto, demonstra-se a importância do contexto escolar e das relações interpessoais para o delineamento de um ambiente que acolha as angústias adolescentes. Um estudo realizado com 11110 estudantes de 168 escolas europeias buscou analisar a relação entre as vítimas de bullying e a ALNS; concluiu que a vitimização relacional e verbal está relacionada a uma maior probabilidade de sintomas depressivos e da realização da autolesão não suicida(19). Considerando a importância do contexto escolar, estudo analisou as relações de apoio dos pais, dos amigos e da escola na ideação e tentativas suicidas nos Estados Unidos. As percepções de apoio parental e da escola foram mais relevantes que o apoio dos amigos ${ }^{(20)}$.

Os adolescentes vivem a oscilação entre a dependência infantil e maturidade adulta, indo e vindo múltiplas vezes entre as duas posições. Assim sendo, são ainda dependentes de pessoas significativas que facilitem o seu desenvolvimento(21). Observa-se, então, que os profissionais de educação têm um papel relevante no desenvolvimento saudável ou não, dos adolescentes. Consequentemente, observa-se a potência destes profissionais em prevenir e enfrentar os casos de ALNS; por estarem próximos longitudinalmente aos adolescentes, possuem maior possibilidade de interação e acesso à função, motivação e significados da ALNS 
para os adolescentes, aspectos cruciais para um cuidado singular e efetivo(6).

No tema "Ações de enfrentamento à ALNS", quando falaram sobre a atuação da escola frente aos casos de ALNS, observamos que há insegurança e dúvida por parte dos profissionais, que se sentem despreparados e pouco qualificados. Ainda assim, nos casos em que a escola se posicionou, seja notificando os pais ou discutindo o tema em sala de aula, as adolescentes referiram alívio e melhora, apontando para a importância do cuidado e do acolhimento no contexto escolar. Estas ações são referenciadas pela literatura como importantes para a satisfação de adolescentes e jovens que recebem o cuidado - o não julgar, a escuta ativa e o envolvimento do adolescente no planejamento de seu cuidado são reforçados ${ }^{(6,22)}$.

Apesar destes profissionais se apresentarem como figuras importantes na conquista do amadurecimento dos adolescentes, nota-se, em suas falas, uma dificuldade de administrar questões relacionadas à ALNS. Declararam que não estava dentro das suas funções, e nem tinham formação para lidar com adolescentes que se autolesionam, Winnicott traz contribuições de grande interesse quanto aos limites da atuação dos profissionais de educação. Ele defende que a função do professor, de fato, não deve ser de tratar seus alunos. 0 potencial de sua atuação vai além desta ideia de tratar, "aconselhar"(23). Um profissional com entendimento sobre o desenvolvimento humano e que favoreça a existência de um ambiente saudável e acolhedor na escola pode auxiliar na prevenção do adoecimento psíquico(17). Para além da prevenção, dentro dos limites do profissional de educação também está visualizar a existência de uma problemática, identificar quando os alunos estão em sofrimento psíquico, se capacitar para compreender e acolher casos de ALNS.

A fala - Aí a Emilia contou pra minha mãe que eu tava me cortando (Letícia) nos leva a discutir ainda mais possibilidades de atuação para estes profissionais de educação frente a ALNS. Primeiro por reconhecer o pedido de ajuda das adolescentes; ademais, pode representar também um ambiente de grande importância para os pais e é, muitas vezes, o único contato destes com orientações profissionais e científicas a respeito do desenvolvimento humano. Além de oferecer orientações, as reuniões entre pais e equipe podem ser oportunidades para que os pais sejam ouvidos, compartilhem e reflitam sobre seus filhos, sobre a relação com eles e sobre si mesmos(17).

Para que a atuação dos profissionais de educação seja responsável e acolhedora frente a casos de ALNS, é fundamental que as condições de trabalho o possibilitem. Tal profissional em um ambiente que também não o sustenta nem acolhe, ao deparar-se com o novo, o inesperado, o doloroso, encontra-se paralisado, apático, incapaz de fornecer cuidados ${ }^{(17)}$. Muitas vezes, a partir do contato com o sofrimento de seus alunos, o profissional é chamado a reviver seus próprios conflitos adolescentes e infantis, e a encarar a diferença entre suas gerações. Diferença de gerações tanto do que é ser um adolescente, quanto do que é ser um professor, do que é sofrimento psicológico, do que é saúde e educação.

As limitações do estudo se direcionam ao número restrito de adolescentes, bem como estrategia de coleta de dados por meio de grupos focais junto aos profissionais; algumas questões poderiam ser melhor aprofundadas individualmente. Reforça-se ainda que o olhar a partir da teoría winicottiana se constitui como uma possibilidade de olhar ao fenómeno. No contexto brasileiro, é urgente a realização de novos estudos que abordem a ALNS pelos atores diretamente envolvidos nela - os adolescentes e jovens, seus familiares e profissionais de equipamentos de saúde e educação.

A despeito das limitações, o presente estudo traz importantes contribuições para o cuidado integral em saude mental adolescente, visto que a intersetorialidade é inerente a tal aspecto. O olhar para a escola, uma instituição de tamanha relevancia à vida dos adolescentes, traz estratégias de ação, seja no reforço de práticas já existentes como no enfrentamento dos desafios encontrados à promoção de saúde mental. A interface saúde-escola, apesar de legitimada por programa específico no Brasil, ainda precisa de esforços para que se efetive na prática; tal estudo traz subsídios para este aprimoramento.

\section{Conclusão}

Os temas "O (não) lugar do sofrimento na escola" e "Ações para enfrentamento da ALNS na escola" permitiram responder ao objetivo inicial, que desvelaram o ambiente escolar como pouco acolhedor ao sofrimento adolescente. A ALNS é um fenómeno complexo e de difícil desenlace, que se articula a diversas situações, dentre elas o bullying. Tem-se assim um ambiente pouco saudavel ao desenvolvimento adolescente. As ações realizadas, mesmo que nao sistemáticas, são reportadas como suporte para enfrentamento da ALNS pelas adolescentes, apesar de pouco legitimadas pelos profissionais da educação.

O ambiente escolar precisa se mobilizar, com apoio interdisciplinar e intersetorial, para que se efetive como promotor do desenvolvimento saudável de adolescentes. Reitera-se que este contexto possui as tecnologias necessárias e potentes para formação de lações, redes, prevenção e enfrentamento do sofrimento de adolescentes. Considerando as prevalências atuais, aspectos de relacionamentos interpessoais, 
inteligência emocional e autocuidado precisam ser inseridos longitudinalmente em currículos escolares. Não obstante, os profissionais da educação também necessitam de cuidado - seja por necessidades de educação permanente quanto pela construção de um espaço ocupacional saudável.

\section{Referências}

1. Fonseca PHN, Silva AC, Araujo LMC, Botti NCL. [Nonsuicidal self-injury intent among adolescentes]. Arq bras psicol [Internet]. 2018 [cited Aug 8, 2019]; 70(3):24658. Available from: http://pepsic.bvsalud.org/pdf/arbp/ v70n3/17.pdf. Portuguese.

2. Giusti JS. Automutilação: características clínicas e comparação com pacientes com transtorno obsessivocompulsivo. [Tese de Doutorado]. São Paulo (SP): Universidade de São Paulo; 2013.

3. Brasil, Ministério da Saúde. Secretaria de vigilância em saúde. Boletim epidemiológico [Internet]. 2017 [cited Jun 8, 2019]; 48(30). Available from: http:// portalarquivos.saude.gov.br/images/pdf/2017/ setembro/21/2017-025-Perfil-epidemiologico-dastentativas-e-obitos-por-suicidio-no-Brasil-e-a-rede-deatencao-a-saude.pdf

4. Mental Health Foundation. The truth about selfharm [Internet]. 2019 [cited Dez 20, 2019]. Available from:http https://www.mentalhealth.org.uk/ publications/truth-about-self-harm.

5. Brasil. Ministéio da Saúde. Proteger e Cuidar de Adolescentes na Atenção Básica. Brasília: Editora do Ministério da Saúde, 2017.

6. Doyle L, Sheridan A, Treacy MP. Motivations for adolescent self-harm and the implications for mental health nurses. J Psychiatr Ment Health Nurs [Internet] 2017;24(2-3). [cited Jan 21 2020]. Available from: https://pubmed.ncbi.nlm.nih.gov/28124465/

7. Silva AC, Botti NCL. Self-injurious behavior along the vital cycle: Integrative literature review. Rev Portuguesa de Enfermagem de Saúde Mental [Internet]. 2017 Dec 18 [Cited Jan 8, 2020]; 67-76. Available from: http:// www.scielo.mec.pt/scielo.phpscript $=$ sci_arttext\&pid=S1 $6472160201700030000 \&$ Ing=pt. Portuguese.

8. Malta DC, Mascarenhas MD, Dias AR, Prado RR. Lima CM, Silva MM, et al. Situations of violence experienced by students in the state capitals and the Federal District: Results from the national adolescent school-based health survey (PeNSE 2012). Revista Brasileira de Epidemiologia, 2015; 17(1), 158-171. doi: 10.1590/1809-4503201400050013.

9. Winnicott DW. O ambiente e os processos de maturação: estudos sobre a teoria do desenvolvimento emocional. Artes Médicas; 1983.

10. Flick U. An introduction to qualitative research. 5th ed. Thousand Oaks, CA: Sage; 2009.
11. Brasil. Ministério da Saúde. Estado de são paulo município de São Carlos. Unidade de Saúde USF Agua Vermelha. Relatório de cadastro individual - Brasília (DF): Ministerio da Saúde; 2018

12. Winnicott DW. Consultas terapêuticas em psiquitria infantil. Rio de Janeiro: Imago; 1984.

13. Aiello-Vaisberg TMJ. Investigação de Representações Sociais. In: W. Trinca (Org.), Formas de investigação clínica em psicologia: procedimento de desenhosestorias: procedimento de desenhos de famílias com estórias. São Paulo: Vetor; 1997. p.255-288

14. Hennink MM, Kaiser BN, Marconi VC. Code saturation versus meaning saturation: how many interviews are enough?. Qual health res. 2017; 27(4):591-608. doi: 10.1177/1049732316665344.

15. Clarke V, Braun V. Teaching thematic analysis: overcoming challenges and developing strategies for effective learning. The Psychologist. [Internet]. 2013 [cited Sep 11, 2019]; 26(2):120-3. Available from: http://eprints.uwe.ac.uk/21155

16. Labrunetti SF. Contribuições de Winnicott para estudo e prevenção da atitude antissocial no ambiente escolar [Tese de Doutorado]. Campinas (SP): Pontifícia Universidade Católica de Campinas; 2014.

17. Baetens I, Van de Ven M, Witteman C. Bullying and victimization, depressive mood, and non-suicidal selfinjury in adolescents: The moderating role of parental support. J Child Fam Stud. 2015; 24(11): 3363-3371. doi: https://doi.org/10.1007/s10826-015-0138-2

18. Klineberg E, Kelly MJ, Stansfeld SA, Bhui KS. How do adolescents talk about self-harm: a qualitative study of disclosure in an ethnically diverse urban population in England. BMC Public Health. 2013 Jun;13:572. doi: 10.1186/1471-2458-13-572

19. Klomek Ab, Snir A, Apter A, Carli V, Wasserman C, Hadlaczky G, et al. Association between victimization by bullying and direct self injurious behavior among adolescence in Europe: a ten-country study. Eur Child Adolesc Psychiatry. 2016; 25(11):1183-93. doi: 10.1007/s00787-016-0840-7

20. Miller AB, Esposito-Smythers C, Leichtweis RN. Role of social support in adolescent suicidal ideation and suicide attempts. J Adolesc Health. 2015 mar;56(3): 286-92. doi: 10.1016/j.jadohealth.2014.10.265

21. Winnicott DW. Adolescência: transpondo a zona das calmarias. In: A família e o desenvolvimento individual. São Paulo: Martins Fontes; 2001. p. 115-128.

22. Mitten N, Preyde M, Lewis S, Vanderkooy J, Heintzman J. The perceptions of adolescents who selfharm on stigma and care following inpatient psychiatric treatment. Soc Work Ment Health. 2016;14(1):1-21. ddoi: 10.1080/15332985.2015.1080783

23. Winnicott DW. O brincar: a atividade criativa e a busca do eu (self). In: O Brincar \& a Realidade. Rio de Janeiro: Imago; 1975. 


\section{Contribuição dos autores}

Concepção e planejamento do estudo: Luiza Cesar Riani Costa, Isabela Martins Gabriel, Daniela Gonsalves Lopes, Wanderlei Abadio de Oliveira, Jorge Luiz da Silva e Diene Monique Carlos. Obtenção dos dados: Luiza Cesar Riani Costa, Isabela Martins Gabriel, Daniela Gonsalves Lopes e Diene Monique Carlos. Análise e interpretação dos dados: Luiza Cesar Riani Costa, Isabela Martins Gabriel, Wanderlei Abadio de Oliveira, Jorge Luiz da Silva e Diene Monique Carlos. Análise estatística: Luiza Cesar Riani Costa, Isabela Martins Gabriel e Diene Monique Carlos. Redação do manuscrito: Luiza Cesar Riani Costa, Isabela Martins Gabriel, Daniela Gonsalves Lopes, Wanderlei Abadio de Oliveira, Jorge Luiz da Silva e Diene Monique Carlos. Revisão crítica do manuscrito: Luiza Cesar Riani Costa, Isabela Martins Gabriel, Daniela Gonsalves Lopes, Wanderlei Abadio de Oliveira, Jorge Luiz da Silva e Diene Monique Carlos.

Todos os autores aprovaram a versão final do texto.

Conflito de interesse: os autores declararam que não há conflito de interesse.

Esta licença permite que outros remixem, adaptem e criem a partir do seu trabalho para fins não comerciais, e embora os novos trabalhos tenham de lhe atribuir o devido crédito e não possam ser usados para fins comerciais, os usuários não têm de licenciar esses trabalhos derivados sob os mesmos termos. 